\title{
The Improved Moving Least-Square Ritz Method for the One-Dimensional Sine-Gordon Equation
}

\author{
Qi Wei and Rongjun Cheng \\ Ningbo Institute of Technology, Zhejiang University, Ningbo 315100, China \\ Correspondence should be addressed to Rongjun Cheng; chengrongjun76@126.com \\ Received 15 December 2013; Accepted 15 January 2014; Published 23 February 2014 \\ Academic Editor: Zan Zhang
}

Copyright (C) 2014 Q. Wei and R. Cheng. This is an open access article distributed under the Creative Commons Attribution License, which permits unrestricted use, distribution, and reproduction in any medium, provided the original work is properly cited.

\begin{abstract}
Analysis of the one-dimensional sine-Gordon equation is performed using the improved moving least-square Ritz method (IMLSRitz method). The improved moving least-square approximation is employed to approximate the 1D displacement field. A system of discrete equations is obtained by application of the Ritz minimization procedure. The effectiveness and accuracy of the IMLS-Ritz method for the sine-Gordon equation are investigated by numerical examples in this paper.
\end{abstract}

\section{Introduction}

It is well known that many physical phenomena in one or higher-dimensional space can be described by a soliton model. Many of these models are based on simple integrable models such as Korteweg-de Vries equation and the nonlinear Schrödinger equation. Solitons have found to model among others shallow-water waves, optical fibres, Josephsonjunction oscillators, and so forth. Equations which also lead to solitary waves are the sine-Gordon. The sine-Gordon equation arises in extended rectangular Josephson junctions, which consist of two layers of super conducting materials separated by an isolating barrier. A typical arrangement is a layer of lead and a layer of niobium separated by a layer of niobium oxide. A quantum particle has a nonzero significant probability of being able to penetrate to the other side of a potential barrier that would be impenetrable to the corresponding classical particle. This phenomenon is usually referred to as quantum tunneling [1-3].

A numerical study for sine-Gordon equation has been proposed including the finite difference schemes [4-6], the finite element methods $[7,8]$, the modified Adomian decomposition method [9], the boundary integral equation approach [10], radius basis function (RBF) [11], the meshless local Petrov-Galerkin (MLPG) [12], the discrete singular convolution [13], meshless local boundary integral equation method (LBIE) [14], the dual reciprocity boundary element method (DRBEM) [15], and the mesh-free kp-Ritz method [16].

The meshless method is a new and interesting numerical technique. Important meshless methods have been developed and proposed, such as smooth particle hydrodynamics methods (SPH) [17], radial basis function (RBF) [18], element free Galerkin method (EFG) [19], meshless local PetrovGalerkin method (MLPG) [20], reproducing kernel particle method (RKPM) [21-23], the boundary element free method (BEFM) [24-27], the complex variable meshless method [2836], improved element free Galerkin method (IEFG) [37-41], and the improved meshless local Petrov-Galerkin method [42-46].

The moving least-square (MLS) technique was originally used for data fitting. Nowadays, the MLS technique has been employed as the shape functions of the meshless method or element-free Galerkin (EFG) method [47]. Though EFG method is now a very popular numerical computational method, a disadvantage of the method is that the final algebraic equations system is sometimes illconditioned. Sometimes a poor solution will be obtained due to the ill-conditioned system. The improved moving leastsquare (IMLS) approximation has been proposed [48-52] to overcome this disadvantage. In the IMLS, the orthogonal function system with a weight function is chosen to be the basis functions. The algebraic equations system in the IMLS approximation will be no more ill-conditioned. 
The Ritz [53] approximation technique is a generalization of the Rayleigh [54] method and it has been widely used in computational mechanics. The element-free kp-Ritz method is firstly developed and implemented for the free vibration analysis of rotating cylindrical panels by Liew et al. [55]. The kp-Ritz method was widely applied and used in many kinds of problems, such as free vibration of two-side simply-supported laminated cylindrical panels [56], nonlinear analysis of laminated composite plates [57], SineGordon equation [16], 3D wave equation [58], and biological population problem [59].

A new numerical method which is named the IMLS-Ritz method for the sine-Gordon equation is presented in this paper. In this paper, the unknown function is approximated by these IMLS approximation; a system of nonlinear discrete equations is obtained by the Ritz minimization procedure, and the boundary conditions are enforced by the penalty method. Numerical examples are presented to validate the accuracy and efficiency of the proposed method.

\section{IMLS-Ritz Formulation for the Sine-Gordon Equation}

Consider the following one-dimensional sine-Gordon equation:

$$
\frac{\partial^{2} u}{\partial t^{2}}+\beta \frac{\partial u}{\partial t}=\frac{\partial^{2} u}{\partial x^{2}}-\sin (u), \quad a \leq x \leq b, 0 \leq t<\infty
$$

with initial conditions

$$
\begin{aligned}
& u(x, 0)=\varphi_{1}(x), \\
& \frac{\partial u(x, 0)}{\partial t}=\varphi_{2}(x)
\end{aligned}
$$

and boundary conditions

$$
u(a, t)=h_{1}(t), \quad u(b, t)=h_{2}(t)
$$

where $\Gamma$ denotes the domain of $x, \Gamma_{u}$ denotes the boundaries, and $\varphi_{1}(x)$ and $\varphi_{2}(x)$ are wave modes or kinks and velocity, respectively. Parameter $\beta$ is the so-called dissipative term, assumed to be a real number with $\beta \geq 0$.

The weighted integral form of (la) is obtained as follows:

$$
\int_{\Gamma} w \cdot\left[\frac{\partial^{2} u}{\partial x^{2}}-\sin (u)-\frac{\partial^{2} u}{\partial t^{2}}-\beta \frac{\partial u}{\partial t}\right] d \Gamma=0 .
$$

The weak form of (2) is

$$
\int_{\Gamma}\left[\nabla^{T} w \nabla u+w \sin (u)+w \frac{\partial^{2} u}{\partial t^{2}}+\beta w \frac{\partial u}{\partial t}\right] d \Gamma=0 .
$$

The energy functional $\Pi(u)$ can be written as

$$
\begin{aligned}
\Pi(u)= & \frac{1}{2} \int_{\Gamma} \nabla^{T} u \cdot \nabla u d \Omega \\
& +\int_{\Gamma}\left[u \frac{\partial^{2} u}{\partial t^{2}}+\beta u \frac{\partial u}{\partial t}+u \sin (u)\right] d \Gamma .
\end{aligned}
$$

In the improved moving least-square approximation [19], define a local approximation by

$$
\mathbf{u}^{\mathbf{h}}(\mathbf{x}, \overline{\mathbf{x}})=\sum_{\mathbf{j}=1}^{\mathbf{m}} \mathbf{p}_{\mathbf{j}}(\overline{\mathbf{x}}) \mathbf{a}_{\mathbf{j}}(\mathbf{x}) \equiv \mathbf{p}^{\mathrm{T}}(\overline{\mathbf{x}})(\mathbf{x})
$$

This defines the quadratic form

$$
J=\sum_{i=1}^{n} w\left(\mathbf{x}-\mathbf{x}_{i}\right)\left[u^{h}\left(\mathbf{x}, \mathbf{x}_{i}\right)-u\left(\mathbf{x}_{i}\right)\right]^{2} .
$$

Equation (6) can be rewritten in the vector form

$$
J=(\mathbf{p a}-\mathbf{u})^{T} \mathbf{W}(\mathbf{x})(\mathbf{p a}-\mathbf{u}) .
$$
by

To find the coefficients $\mathbf{a}(\mathbf{x})$, we obtain the extremum of $J$

$$
\frac{\partial \mathbf{J}}{\partial \mathbf{a}}=\mathbf{A}(\mathbf{x}) \mathbf{a}(\mathbf{x})-\mathbf{B}(\mathbf{x}) \mathbf{u}=0
$$

which results in the equation system

$$
\mathbf{A}(\mathbf{x}) \mathbf{a}(\mathbf{x})=\mathbf{B}(\mathbf{x}) \mathbf{u} \text {. }
$$

If the functions $p_{1}(\mathbf{x}), p_{2}(\mathbf{x}), \ldots, p_{m}(\mathbf{x})$ satisfy the conditions

$$
\begin{array}{r}
\left(p_{k}, p_{j}\right)=\sum_{i=1}^{n} w_{i} p_{k}\left(\mathbf{x}_{i}\right) p_{j}\left(\mathbf{x}_{i}\right)= \begin{cases}0 & k \neq j \\
A_{k} & k=j\end{cases} \\
(k, j=1,2, \ldots, m),
\end{array}
$$

then $p_{1}(\mathbf{x}), p_{2}(\mathbf{x}), \ldots, p_{m}(\mathbf{x})$ is called a weighted orthogonal function set with a weight function $\left\{w_{i}\right\}$ about points $\left\{\mathbf{x}_{i}\right\}$. The weighted orthogonal basis function set $\mathbf{p}=\left(p_{i}\right)$ can be formed with the Schmidt method [39-41],

$$
\begin{gathered}
p_{1}=1 \\
p_{i}=r^{i-1}-\sum_{k=1}^{i-1} \frac{\left(r^{i-1}, p_{k}\right)}{\left(p_{k}, p_{k}\right)} p_{k}, \quad i=2,3, \ldots
\end{gathered}
$$

Equation (9) can be rewritten as

$$
\left[\begin{array}{cccc}
\left(p_{1}, p_{1}\right) & 0 & \cdots & 0 \\
0 & \left(p_{2}, p_{2}\right) & \cdots & 0 \\
\vdots & \vdots & \ddots & \vdots \\
0 & 0 & \cdots & \left(p_{m}, p_{m}\right)
\end{array}\right]\left[\begin{array}{c}
a_{1}(\mathbf{x}) \\
a_{2}(\mathbf{x}) \\
\vdots \\
a_{m}(\mathbf{x})
\end{array}\right]=\left[\begin{array}{c}
\left(p_{1}, u_{I}\right) \\
\left(p_{2}, u_{I}\right) \\
\vdots \\
\left(p_{m}, u_{I}\right)
\end{array}\right]
$$

The coefficients $a_{i}(\mathbf{x})$ can be directly obtained as follows:

$$
a_{i}(\mathbf{x})=\frac{\left(p_{i}, u_{I}\right)}{\left(p_{i}, p_{i}\right)} ; \quad(i=1,2, \ldots, m) ;
$$

(4) that is,

$$
\mathbf{a}(\mathbf{x})=\overline{\mathbf{A}}(\mathbf{x}) \mathbf{B}(\mathbf{x}) \mathbf{u},
$$


where

$$
\overline{\mathbf{A}}(\mathbf{x})=\left[\begin{array}{cccc}
\frac{1}{\left(p_{1}, p_{1}\right)} & 0 & \cdots & 0 \\
0 & \frac{1}{\left(p_{2}, p_{2}\right)} & \cdots & 0 \\
\vdots & \vdots & \ddots & \vdots \\
0 & 0 & \cdots & \frac{1}{\left(p_{m}, p_{m}\right)}
\end{array}\right] .
$$

From (12), the approximation function $u^{h}(\mathbf{x})$ can be rewritten as

$$
u^{h}(\mathbf{x})=\bar{\Phi}(\mathbf{x}) \mathbf{u}=\sum_{I=1}^{n} \bar{\Phi}_{I}(\mathbf{x}) u_{I}
$$

where $\bar{\Phi}(\mathbf{x})$ is the shape function and

$$
\bar{\Phi}(\mathbf{x})=\left(\bar{\Phi}_{1}(\mathbf{x}), \bar{\Phi}_{2}(\mathbf{x}), \ldots, \bar{\Phi}_{n}(\mathbf{x})\right)=\mathbf{p}^{T}(\mathbf{x}) \overline{\mathbf{A}}(\mathbf{x}) \mathbf{B}(\mathbf{x}) .
$$

Taking derivatives of (17), we can obtain the first derivatives of shape function

$$
\bar{\Phi}_{I, i}(\mathbf{x})=\sum_{j=1}^{m}\left[p_{j, i}(\overline{\mathbf{A}} \mathbf{B})_{j I}+p_{j}\left(\overline{\mathbf{A}}_{, i} \mathbf{B}+\overline{\mathbf{A}} \mathbf{B}_{, i}\right)_{j I}\right] .
$$

Imposing boundary conditions by penalty method, the total energy functional for this problem will be obtained:

$$
\begin{aligned}
\Pi^{*}(u)= & \frac{1}{2} \int_{\Gamma} \nabla^{T} u \cdot \nabla u d \Omega \\
& +\int_{\Gamma}\left[u \frac{\partial^{2} u}{\partial t^{2}}+\beta u \frac{\partial u}{\partial t}+u \sin (u)\right] d \Gamma \\
& +\frac{\alpha}{2} \int_{S}(u-\bar{u})^{2} d S .
\end{aligned}
$$

By (16), we can derive the approximation function

$$
\begin{aligned}
u^{h}(x, t) & =\sum_{I=1}^{n} \Phi_{I}(x) \cdot T_{I}(t)=\Phi(x) \cdot \mathbf{T}, \\
\frac{\partial u(x, t)}{\partial t} & =\frac{\partial}{\partial t} \sum_{I=1}^{n} \Phi_{I}(x) \cdot T_{I}(t) \\
& =\sum_{I=1}^{n} \Phi_{I}(x) \cdot \frac{\partial T_{I}(t)}{\partial t}=\Phi(x) \dot{\mathbf{T}}, \\
\frac{\partial^{2} u(x, t)}{\partial t^{2}} & =\frac{\partial^{2}}{\partial t^{2}} \sum_{I=1}^{n} \Phi_{I}(x) \cdot T_{I}(t) \\
& =\sum_{I=1}^{n} \Phi_{I}(x) \cdot \frac{\partial^{2} T_{I}(t)}{\partial t^{2}}=\Phi(x) \ddot{\mathbf{T}} .
\end{aligned}
$$

Substituting (20) into (19) and applying the Ritz minimization procedure to the energy function $\Pi^{*}(u)$, we obtain

$$
\begin{array}{r}
\frac{\partial \Pi^{*}(u)}{\partial \Delta}=0, \quad \Delta=T_{I}(t), \frac{\partial T_{I}(t)}{\partial t}, \frac{\partial^{2} T_{I}(t)}{\partial t^{2}}, \\
I=1,2, \ldots, n .
\end{array}
$$

In the matrix form, the results can be expressed as

$$
\mathbf{C} \ddot{\mathbf{T}}+\beta \mathbf{C} \dot{\mathbf{T}}+\mathbf{K T}=\mathbf{F},
$$

where

$$
\begin{gathered}
C_{I J}=\int_{\Gamma} \Phi_{I}(x) \Phi_{J}(x) d \Gamma \\
K_{I J}=\int_{\Gamma} \nabla \Phi_{I}^{T}(\mathbf{x}) \nabla \Phi_{J}(\mathbf{x}) d \Gamma+\alpha\left(\left.\Phi_{I} \Phi_{J}\right|_{x=a}+\left.\Phi_{I} \Phi_{J}\right|_{x=b}\right), \\
F_{I}=-\int_{\Gamma} \Phi_{I}(x) \sin (T) d \Gamma+\alpha\left(\left.\Phi_{I} \bar{u}\right|_{x=a}+\left.\Phi_{I} \bar{u}\right|_{x=b}\right) .
\end{gathered}
$$

Making time discretization of (22) by the center difference method, we get

$$
\begin{aligned}
& \mathbf{C} \frac{\mathbf{T}^{(k+2)}-2 \mathbf{T}^{(k+1)}+\mathbf{T}^{(k)}}{\Delta t^{2}} \\
& +\beta \mathbf{C} \frac{\mathbf{T}^{(k+1)}-\mathbf{T}^{(k)}}{\Delta t}+\mathbf{K} \frac{\mathbf{T}^{(k+1)}+\mathbf{T}^{(k)}}{2}=\mathbf{F},
\end{aligned}
$$

where

$$
\begin{gathered}
\mathbf{T}^{(k)}=\mathbf{T}\left(t_{k}\right)=\left(T_{1}\left(t_{k}\right), T_{2}\left(t_{k}\right), \ldots, T_{n}\left(t_{k}\right)\right), \\
F_{I}=-\int_{\Gamma} \Phi_{I}(x) d \Gamma \cdot \sin (\widetilde{T})+\alpha\left(\left.\Phi_{I} \bar{u}\right|_{x=a}+\left.\Phi_{I} \bar{u}\right|_{x=b}\right) .
\end{gathered}
$$

The numerical solution of the one-dimensional sineGordon equation will be obtained by solving the above iteration equation.

\section{Numerical Examples and Analysis}

To verify the efficiency and accuracy of the proposed IMLSRitz method for the sine-Gordon equation, two examples are studied and the numerical results are presented. The weight function is chosen to be cubic spline and the bases are chosen to be linear in all examples.

Example 1. Consider the sine-Gordon Equation (1a)-(1d) without nonlinear term $\sin (u)$ over the region $-1 \leq x \leq 1$ with initial conditions

$$
\begin{gathered}
u(x, 0)=\varphi_{1}(x)=\sin (\pi x) \\
u_{t}(x, 0)=\varphi_{2}(x)=0
\end{gathered}
$$

with boundary conditions

$$
u(-1, t)=u(1, t)=0
$$

The exact solution is

$$
u(x, t)=\frac{1}{2}(\sin \pi(x+t)+\sin \pi(x-t)) .
$$


TABLE 1: The comparisons of exact solution with numerical solutions by IEFG and EFG methods with 41 nodes at $t=0.1$ with $d t=0.001$ and $d_{\max }=3.0$ (Example 1).

\begin{tabular}{lccc}
\hline Node number & Exact solution & IMLS-Ritz method & EFG method \\
\hline 21 & 0.1488 & 0.1479 & 0.1473 \\
22 & 0.2939 & 0.2918 & 0.2909 \\
23 & 0.4318 & 0.4297 & 0.4275 \\
24 & 0.5590 & 0.5583 & 0.5536 \\
25 & 0.6725 & 0.6732 & 0.6661 \\
26 & 0.7694 & 0.7687 & 0.7653 \\
27 & 0.8474 & 0.8471 & 0.8399 \\
28 & 0.9045 & 0.9032 & 0.8989 \\
29 & 0.9393 & 0.9389 & 0.9380 \\
30 & 0.8474 & 0.8478 & 0.8487 \\
31 & 0.7694 & 0.7685 & 0.7625 \\
32 & 0.6725 & 0.6732 & 0.6753 \\
\hline
\end{tabular}

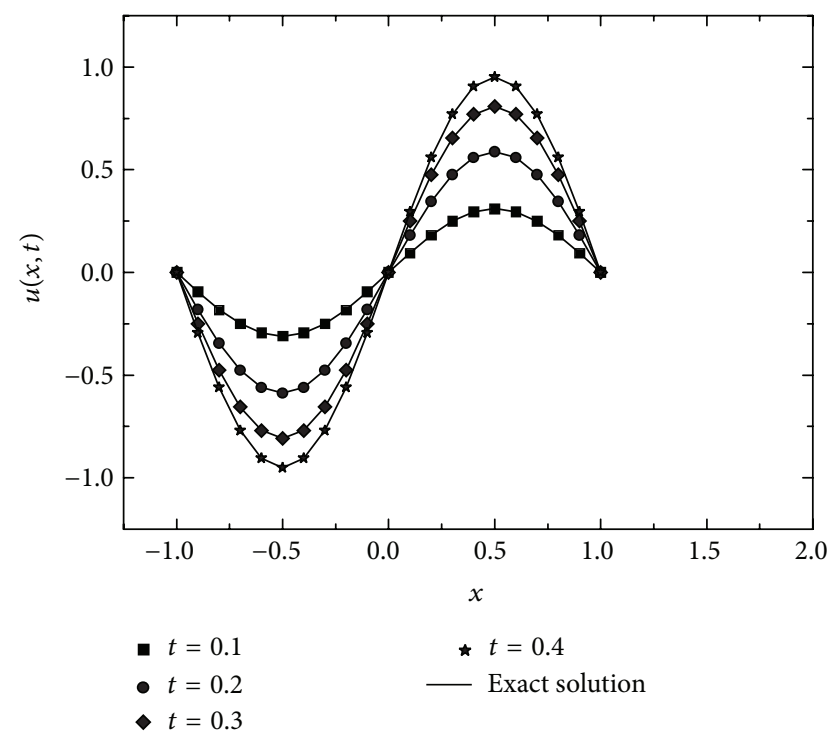

FIGURE 1: Numerical solution and exact solution of $u(x, t)$ when $t=$ $0.1,0.2,0.3,0.4$ (Example 1).

The IMLS-Ritz method is applied to solve the above equation with penalty factor $\alpha=10^{4}$ and time step length $\Delta t=0.001, d_{\max }=3.0$. In Figure 1, the numerical solution and exact solution are plotted at times $t=0.1,0.2,0.3$, and 0.4 , respectively. In Figures 2, 3, and 4, the graphs of error function $u^{h}(x, t)-u(x, t)$ are plotted at times $t=0.1$, 0.2 , and 0.3 , respectively, where $u(x, t)$ is the exact solution and numerical solution $u^{h}(x, t)$ is obtained by using the IMLS-Ritz method. Table 1 shows the comparison of exact solutions and numerical solutions by IMLS-Ritz method and EFG method. From the results of Table 1, we can draw the conclusion that IMLS-Ritz method has higher accuracy than the EFG method. The surfaces of the numerical solution with the IMLS-Ritz method and exact solutions are plotted in Figures 5 and 6.

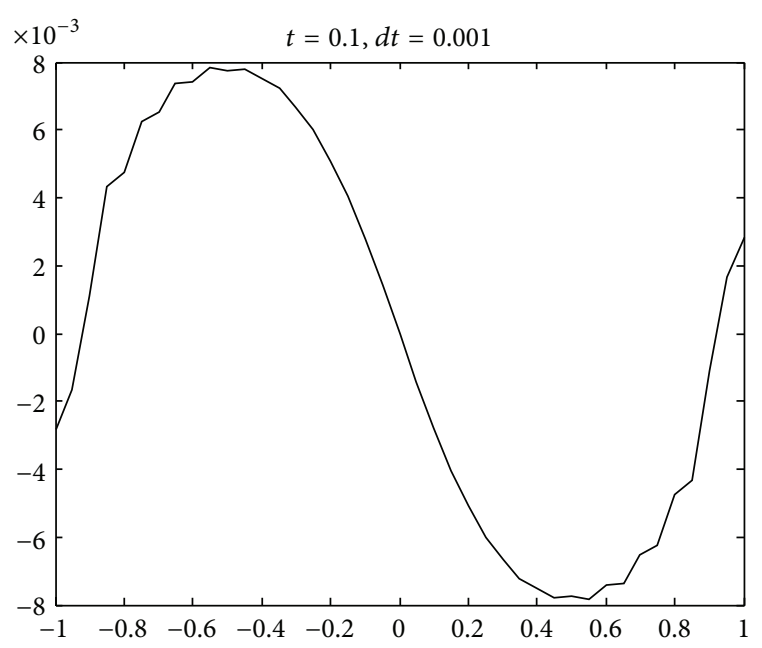

FIGURE 2: Error function $u^{h}(x, t)-u(x, t)$, where $u(x, t)$ is an exact solution and numerical solution $u^{h}(x, t)$ is obtained by using the IMLS-Ritz method with $d t=0.001$ at $t=0.1$ (Example 1).

Example 2. Consider the case $\beta=0$ in (1a)-(1d) over the rectangular region $-20 \leq x \leq 20$ and initial condition

$$
\begin{gathered}
u(x, 0)=\varphi_{1}(x)=0, \\
u_{t}(x, 0)=\varphi_{2}(x)=4 \operatorname{sech}(x)
\end{gathered}
$$

which derives the analytic solution

$$
u(x, t)=4 \tan ^{-1}(\operatorname{sech}(x t))
$$

and the boundary conditions can be obtained from (30).

The IMLS-Ritz method is applied to solve the above equation with penalty factor $\alpha=10^{5}$ and time step length $\Delta t=0.01, d_{\max }=2.2$. Figure 7 depicts the numerical and exact solution when $t=1,5,10,20$, and 30 , respectively. In Figures 8,9 , and 10, the graphs of error function $u^{h}(x, t)-$ $u(x, t)$ are plotted at times $t=1,5$, and 10 , respectively, where 


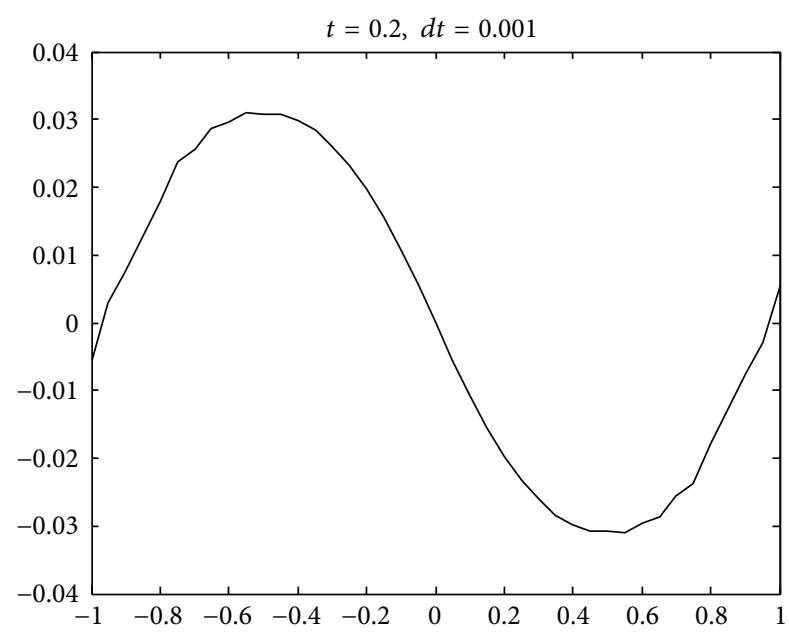

FIGURE 3: Error function $u^{h}(x, t)-u(x, t)$, where $u(x, t)$ is an exact solution and numerical solution $u^{h}(x, t)$ is obtained by using the IMLS-Ritz method with $d t=0.001$ at $t=0.2$ (Example 1).

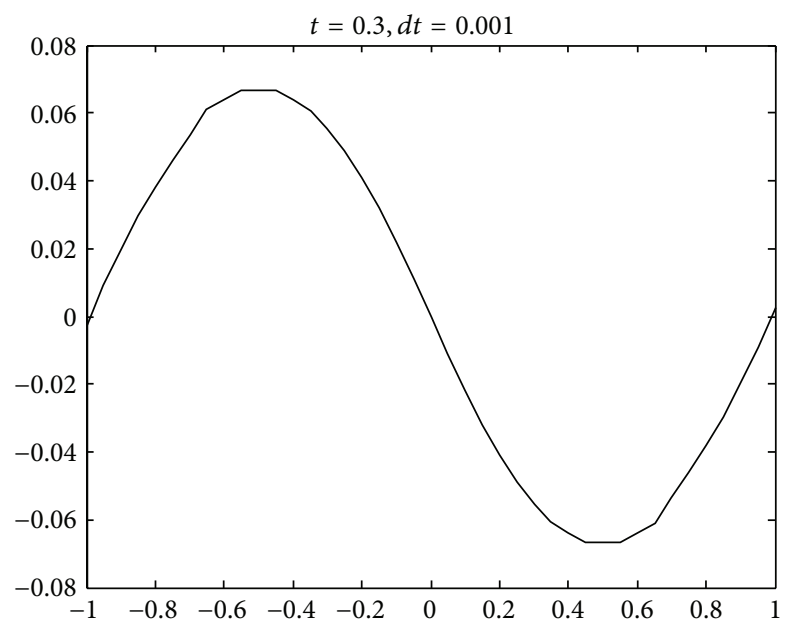

FIGURE 4: Error function $u^{h}(x, t)-u(x, t)$, where $u(x, t)$ is an exact solution and numerical solution $u^{h}(x, t)$ is obtained by using the IMLS-Ritz method with $d t=0.001$ at $t=0.3$ (Example 1).

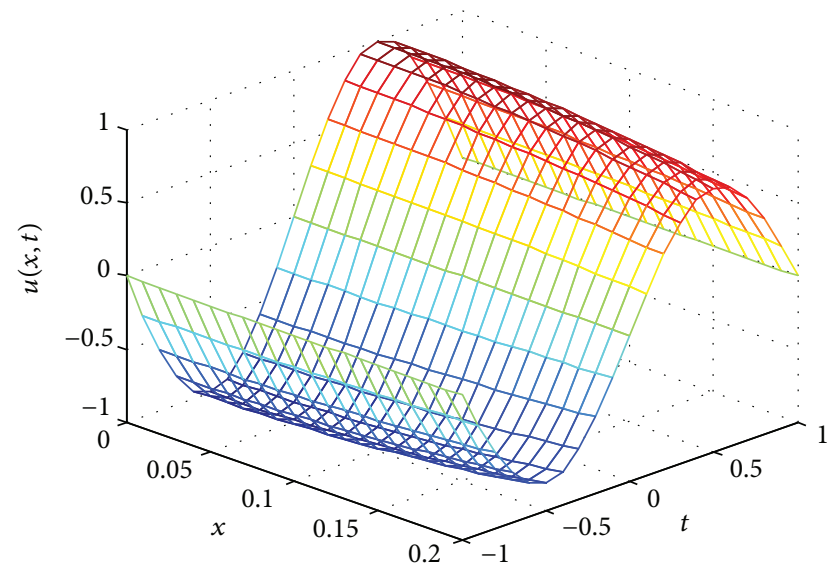

FIgURE 5: The surface of exact solution (Example 1).

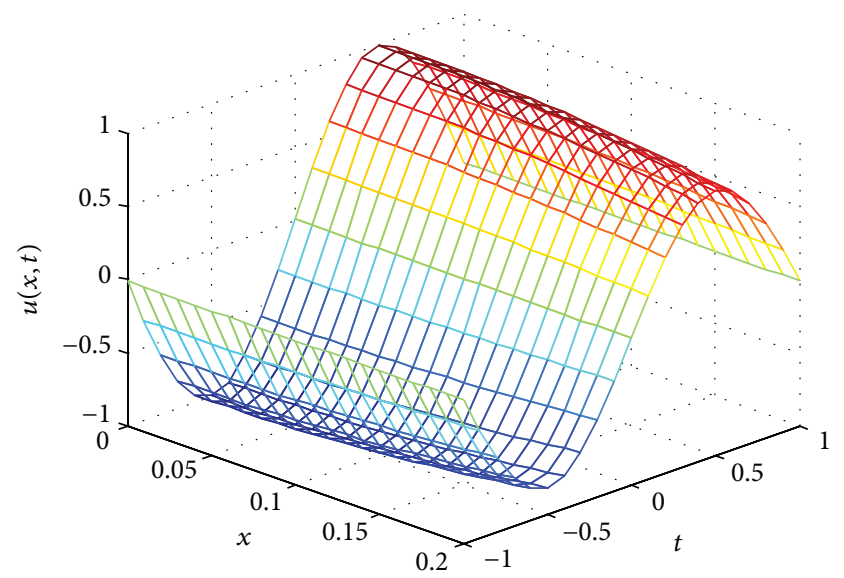

FIGURE 6: The surface of numerical solution with IMLS-Ritz method (Example 1).

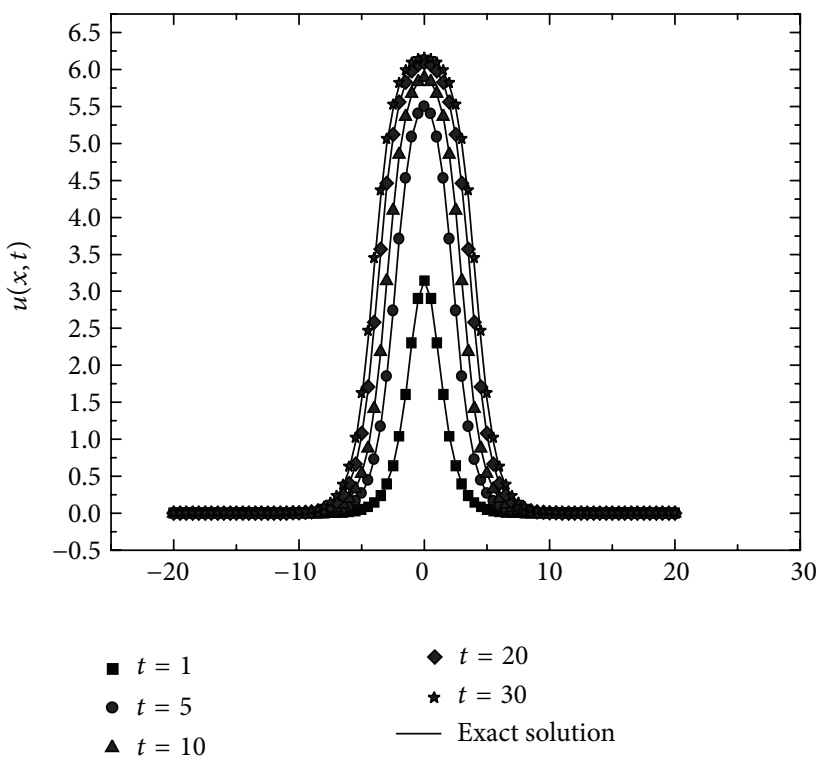

FIGURE 7: Numerical solution and exact solution of $u(x, t)$ when $t=$ 1, 5, 10, 20, 30 (Example 2).

$u(x, t)$ is the exact solution and numerical solution $u^{h}(x, t)$ is obtained by using the IMLS-Ritz method. Table 2 shows the comparison of exact solutions and numerical solutions by IMLS-Ritz method and EFG method. From the results of Table 2, it is shown that IMLS-Ritz method has higher accuracy than the EFG method. The surfaces of the numerical solution with the IMLS-Ritz method and exact solution are plotted in Figures 11 and 12.

Example 3. Consider the case in (1a)-(1d) over the rectangular region $-20 \leq x \leq 20$ and initial condition

$$
\begin{gathered}
u(x, 0)=\varphi_{1}(x)=4 \arctan \left(e^{\eta}\right), \\
u_{t}(x, 0)=\varphi_{2}(x)=-\frac{4 c e^{\eta}}{\sqrt{1-c^{2}}\left(1+e^{2 \eta}\right)}
\end{gathered}
$$




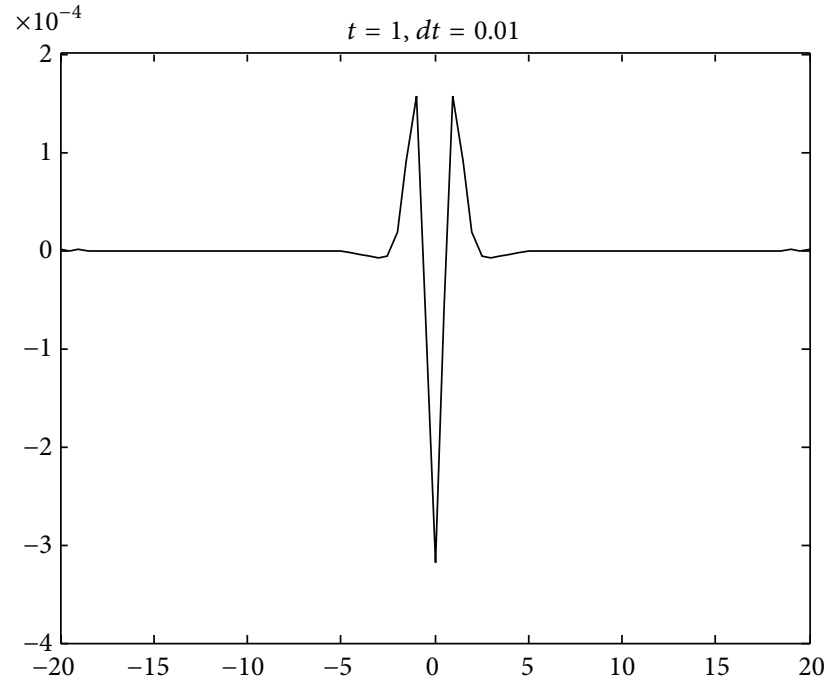

FIGURE 8: Error function $u^{h}(x, t)-u(x, t)$ with $d t=0.01$ at $t=1$ (Example 2).

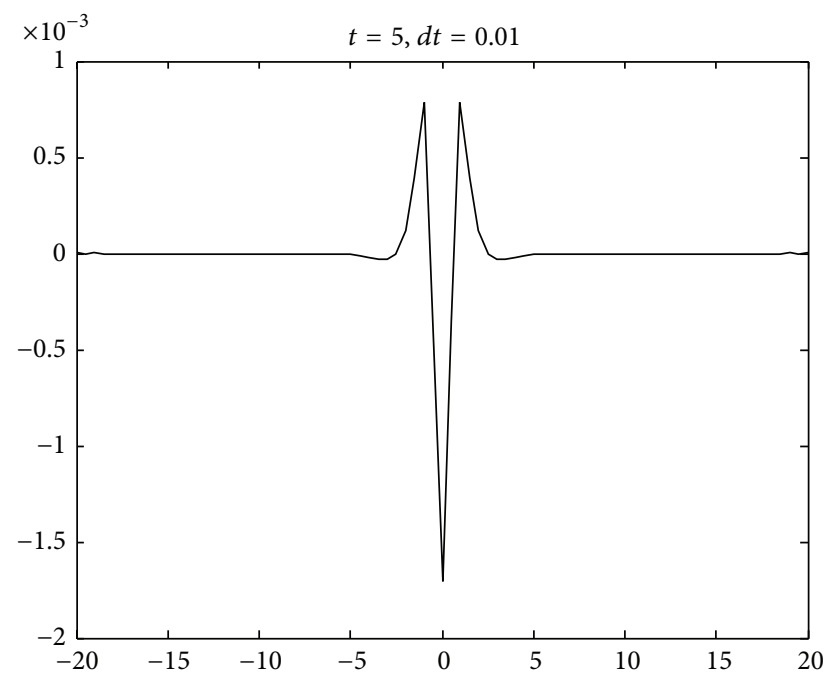

Figure 9: Error function $u^{h}(x, t)-u(x, t)$ with $d t=0.01$ at $t=5$ (Example 2).

and the boundary conditions can be derived from the following exact solitary wave solution:

$$
u(x, t)=4 \arctan \left(e^{(x-c t) / \sqrt{1-c^{2}}}\right),
$$

where $\eta=x / \sqrt{1-c^{2}}$ and $c$ is the velocity of solitary wave.

The IMLS-Ritz method is applied to solve the above equation with penalty factor $\alpha=10^{7}$ and time step length $\Delta t=0.01, d_{\max }=2.7, c=0.5$. Table 3 shows the comparison of exact solutions and numerical solutions by IMLS-Ritz method and EFG method. From the results of Table 3, it is shown that IMLS-Ritz method has higher accuracy than the EFG method. The surfaces of the numerical solution with the IMLS-Ritz method and exact solution are plotted in Figures

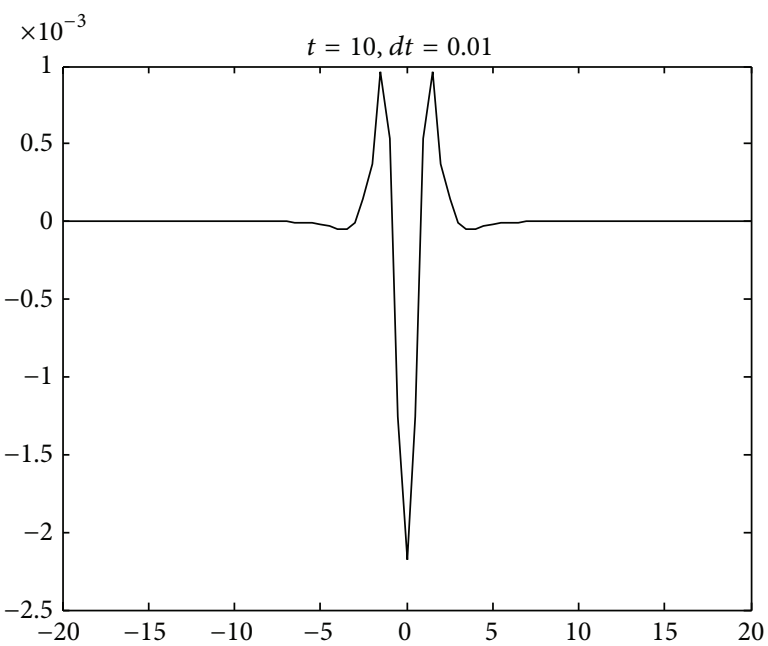

FIgURE 10: Error function $u^{h}(x, t)-u(x, t)$ with $d t=0.01$ at $t=10$ (Example 2).

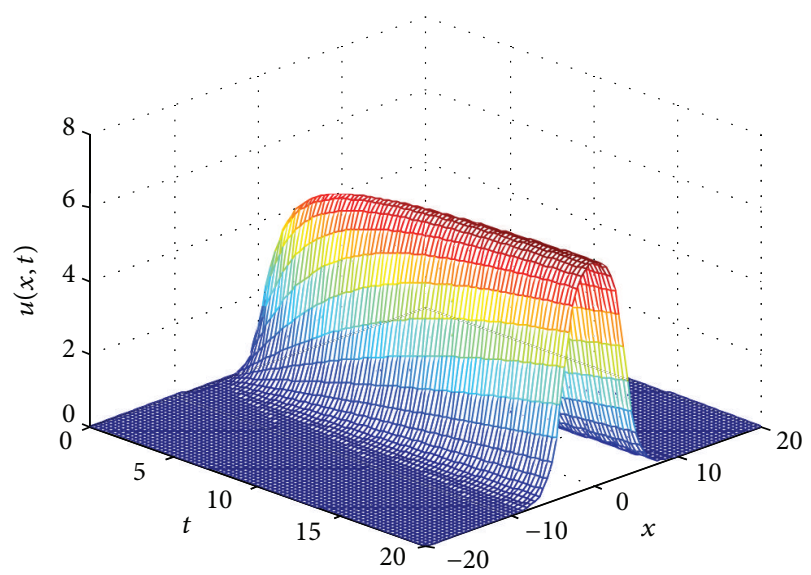

FIgURE 11: The surface of exact solution (Example 2).

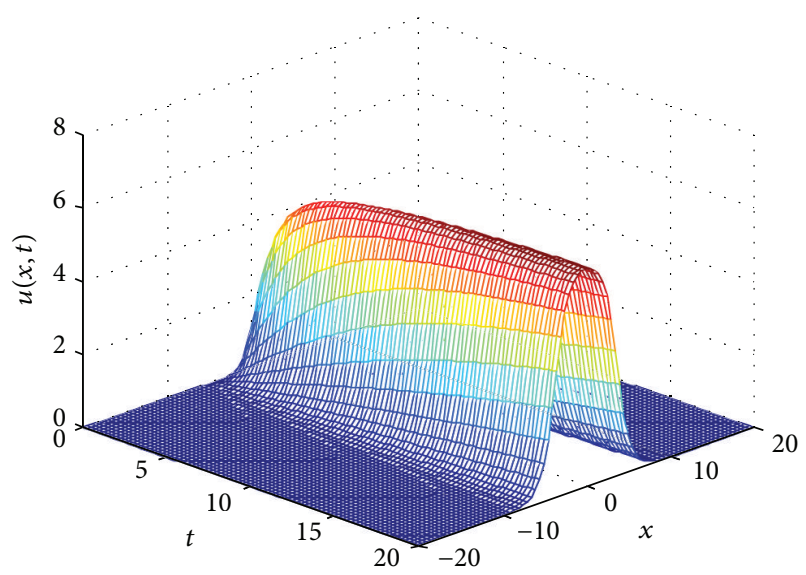

FIGURE 12: The surface of numerical solution with IMLS-Ritz method (Example 2). 
TABLE 2: The comparisons of exact solution with numerical solutions by IEFG and EFG methods with 40 nodes at $t=1$ with $d t=0.01$ and $d_{\max }=2.2$ (Example 2).

\begin{tabular}{lccc}
\hline Node number & Exact solution & IMLS-Ritz method & EFG method \\
\hline 10 & 0.0001 & 0.0001 & 0.0001 \\
11 & 0.0004 & 0.0004 & 0.0004 \\
12 & 0.0010 & 0.0010 & 0.0010 \\
13 & 0.0027 & 0.0027 & 0.0026 \\
14 & 0.0073 & 0.0072 & 0.0074 \\
15 & 0.0198 & 0.0197 & 0.0196 \\
16 & 0.0539 & 0.0536 & 0.0535 \\
17 & 0.1464 & 0.1463 & 0.1462 \\
18 & 0.3960 & 0.3958 & 0.3956 \\
19 & 1.0392 & 1.0396 & 1.0442 \\
20 & 2.3000 & 2.2993 & 2.2989 \\
21 & 3.1416 & 3.1408 & 3.1406 \\
\hline
\end{tabular}

TABLE 3: The comparisons of exact solution with numerical solutions by IEFG and EFG methods with 81 nodes at $t=1$ with $d t=0.001$ and $d_{\max }=2.7$ (Example 3).

\begin{tabular}{lccc}
\hline Node number & Exact solution & IMLS-Ritz method & EFG method \\
\hline 30 & 0.0039 & 0.0037 & 0.0036 \\
31 & 0.0070 & 0.0068 & 0.0059 \\
32 & 0.0124 & 0.0125 & 0.0131 \\
33 & 0.0222 & 0.0231 & 0.0229 \\
34 & 0.0395 & 0.0402 & 0.0423 \\
35 & 0.0703 & 0.0710 & 0.0722 \\
36 & 0.1252 & 0.1251 & 0.1253 \\
37 & 0.2228 & 0.2225 & 0.2231 \\
38 & 0.3960 & 0.3948 & 0.3952 \\
39 & 0.7004 & 0.6978 & 0.6988 \\
40 & 1.2212 & 1.2209 & 1.2301 \\
41 & 2.0462 & 2.0471 & 2.0483 \\
\hline
\end{tabular}

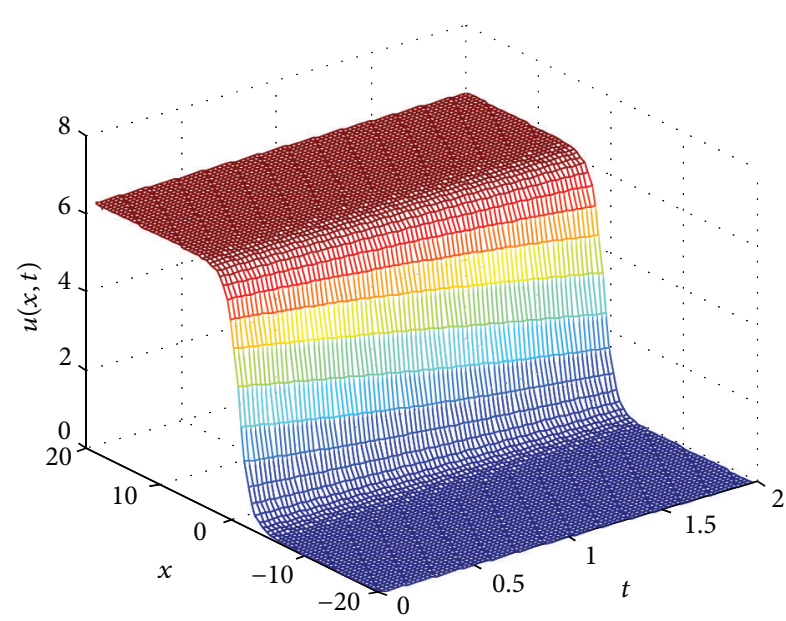

FIGURE 13: The surface of exact solution (Example 3).

13 and 14. In Figure 15, the graph of error function $u^{h}(x, t)-$ $u(x, t)$ is plotted at time $t=1$, where $u(x, t)$ is the exact

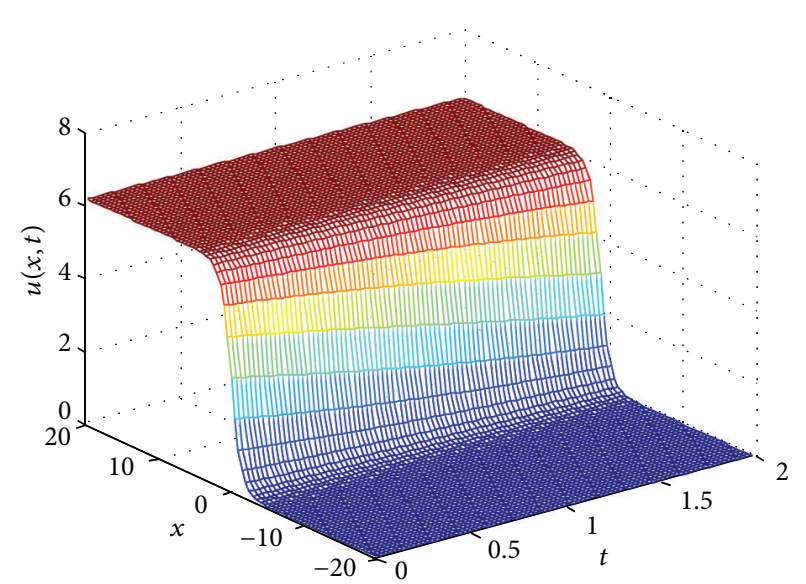

FIGURE 14: The surface of numerical solution with IMLS-Ritz method (Example 3).

solution and the numerical solution $u^{h}(x, t)$ is obtained by using the IMLS-Ritz method. 


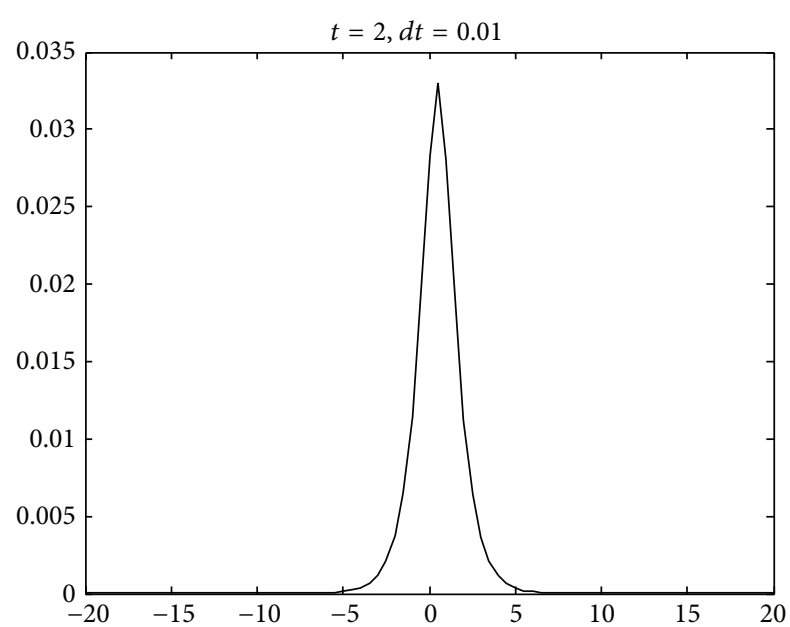

FIGURE 15: Error function $u^{h}(x, t)-u(x, t)$ with $d t=0.01$ at $t=2$ (Example 3).

From these figures, it is shown that numerical results obtained by the IMLS-Ritz method are in good agreement with the exact solutions.

\section{Conclusion}

This paper presents a numerical method, named the IMLSRitz method, for the one-dimensional sine-Gordon equation. The IMLS approximation is employed to approximate the $1 \mathrm{D}$ displacement field. A system of discrete equations is obtained through application of the Ritz minimization. In the IMLS approximation, the basis function is chosen as the orthogonal function system with a weight function. The IMLS approximation has greater computational efficiency and precision than the MLS approximation, and it does not lead to an ill-conditioned system of equations. The numerical results show that the technique is accurate and efficient.

\section{Conflict of Interests}

The authors declare that there is no conflict of interests regarding the publication of this paper.

\section{Acknowledgments}

This work was supported by the National Natural Science Foundation of Ningbo City (Grant nos. 2013A610067, 2102A610023, and 2013A610103), the Natural Science Foundation of Zhejiang Province of China (Grant no. Y6110007), and the National Natural Science of China (Grant no. 41305016).

\section{References}

[1] R. K. Dodd, J. C. Eilbeck, J. D. Gibbon, and H. C. Morris, Solitons and Nonlinear Wave Equations, Academic Press, London, UK, 1982.

[2] A. Barone, F. Esposito, C. J. Magee, and A. C. Scott, "Theory and applications of the sine-gordon equation," La Rivista del Nuovo
Cimento, vol. 1, no. 2, pp. 227-267, 1971.

[3] M. Dehghan and A. Shokri, "A numerical method for onedimensional nonlinear sine-Gordon equation using collocation and radial basis functions," Numerical Methods Partial Differential Equations, vol. 79, no. 3, pp. 700-715, 2008.

[4] M. Cui, "Fourth-order compact scheme for the onedimensional Sine-Gordon equation," Numerical Methods for Partial Differential Equations, vol. 25, no. 3, pp. 685-711, 2009.

[5] A. Q. M. Khaliq, B. Abukhodair, Q. Sheng, and M. S. Ismail, "A predictor-corrector scheme for the sine-Gordon equation," Numerical Methods for Partial Differential Equations, vol. 16, no. 2, pp. 133-146, 2000.

[6] J. I. Ramos, "The sine-Gordon equation in the finite line," Applied Mathematics and Computation, vol. 124, no. 1, pp. 4593, 2001.

[7] J. Argyris and M. Haase, “An engineer's guide to soliton phenomena: application of the finite element method," Computer Methods in Applied Mechanics and Engineering, vol. 61, no. 1, pp. 71-122, 1987.

[8] J. Argyris, M. Haase, and J. C. Heinrich, "Finite element approximation to two-dimensional sine-Gordon solitons," Computer Methods in Applied Mechanics and Engineering, vol. 86, no. 1, pp. 1-26, 1991.

[9] D. Kaya, "A numerical solution of the sine-Gordon equation using the modified decomposition method," Applied Mathematics and Computation, vol. 143, no. 2-3, pp. 309-317, 2003.

[10] M. Dehghan and D. Mirzaei, “The boundary integral equation approach for numerical solution of the one-dimensional sineGordon equation," Numerical Methods for Partial Differential Equations, vol. 24, no. 6, pp. 1405-1415, 2008.

[11] M. Dehghan and A. Shokri, "A numerical method for solution of the two-dimensional sine-Gordon equation using the radial basis functions," Mathematics and Computers in Simulation, vol. 79, no. 3, pp. 700-715, 2008.

[12] D. Mirzaei and M. Dehghan, "Meshless local Petrov-Galerkin (MLPG) approximation to the two dimensional sine-Gordon equation," Journal of Computational and Applied Mathematics, vol. 233, no. 10, pp. 2737-2754, 2010.

[13] G. W. Wei, "Discrete singular convolution for the sine-Gordon equation," Physica D, vol. 137, no. 3-4, pp. 247-259, 2000.

[14] D. Mirzaei and M. Dehghan, "Implementation of meshless LBIE method to the 2D non-linear SG problem," International Journal for Numerical Methods in Engineering, vol. 79, no. 13, pp. 1662$1682,2009$.

[15] M. Dehghan and D. Mirzaei, "The dual reciprocity boundary element method (DRBEM) for two-dimensional sine-Gordon equation," Computer Methods in Applied Mechanics and Engineering, vol. 197, no. 6-8, pp. 476-486, 2008.

[16] R. J. Cheng and K. M. Liew, "Analyzing two-dimensional sine-Gordon equation with the mesh-free reproducing kernel particle Ritz method," Computer Methods in Applied Mechanics and Engineering, vol. 245/246, pp. 132-143, 2012.

[17] J. J. Monaghan, "An introduction to SPH," Computer Physics Communications, vol. 48, no. 1, pp. 89-96, 1988.

[18] W. Chen, Meshfree Methods for Partial Differential Equations, Springer, 2003.

[19] T. Belytschko, Y. Y. Lu, and L. Gu, "Element-free Galerkin methods," International Journal for Numerical Methods in Engineering, vol. 37, no. 2, pp. 229-256, 1994. 
[20] S. N. Atluri and T. Zhu, "A new meshless local Petrov-Galerkin (MLPG) approach in computational mechanics," Computational Mechanics, vol. 22, no. 8-9, pp. 117-127, 1998.

[21] Y. X. Qin and Y. M. Cheng, "Reproducing kernel particle boundary element-free method for potential problems," Chinese Journal of Theoretical and Applied Mechanics, vol. 41, no. 6, pp. 898-905, 2009.

[22] R. Cheng and K. M. Liew, "The reproducing kernel particle method for two-dimensional unsteady heat conduction problems," Computational Mechanics, vol. 45, no. 2, pp. 1-10, 2009.

[23] R. J. Cheng and K. M. Liew, "A meshless analysis of threedimensional transient heat conduction problems," Engineering Analysis with Boundary Elements, vol. 36, no. 2, pp. 203-210, 2012.

[24] Y. Cheng and M. Peng, "Boundary element-free method for elastodynamics," Science in China G, vol. 48, no. 6, pp. 641-657, 2005.

[25] M. Peng and Y. Cheng, "A boundary element-free method (BEFM) for two-dimensional potential problems," Engineering Analysis with Boundary Elements, vol. 33, no. 1, pp. 77-82, 2009.

[26] J. Wang, J. Wang, F. Sun, and Y. Cheng, "An interpolating boundary element-free method with nonsingular weight function for two-dimensional potential problems," International Journal of Computational Methods, vol. 10, no. 6, Article ID 1350043, 2013.

[27] K. M. Liew, Y. Cheng, and S. Kitipornchai, "Analyzing the 2D fracture problems via the enriched boundary element-free method," International Journal of Solids and Structures, vol. 44, no. 11-12, pp. 4220-4233, 2007.

[28] Y. Cheng and J. Li, "Complex variable meshless method for fracture problems," Science in China G, vol. 49, no. 1, pp. 46-59, 2006.

[29] M. Peng, P. Liu, and Y. Cheng, "The complex variable elementfree Galerkin (CVEFG) method for two-dimensional elasticity problems," International Journal of Applied Mechanics, vol. 1, no. 2, pp. 367-385, 2009.

[30] L. Chen and Y. M. Cheng, "The complex variable reproducing kernel particle method for elasto-plasticity problems," Science China, vol. 53, no. 5, pp. 954-965, 2010.

[31] M. Peng, D. Li, and Y. Cheng, "The complex variable elementfree Galerkin (CVEFG) method for elasto-plasticity problems," Engineering Structures, vol. 33, no. 1, pp. 127-135, 2011.

[32] Y. M. Cheng, R. X. Li, and M. J. Peng, "Complex variable element-free Galerkin (CVEFG) method for viscoelasticity problems," Chinese Physics B, vol. 21, no. 9, Article ID 090205, 2012.

[33] J. F. Wang and Y. M. Cheng, "A new complex variable meshless method for transient heat conduction problems," Chinese Physics B, vol. 21, no. 12, Article ID 120206, 2012.

[34] Y. M. Cheng, J. F. Wang, and R. X. Li, "The complex variable element-free Galerkin (CVEFG) method for two-dimensional elastodynamics problems," International Journal of Applied Mechanics, vol. 4, no. 4, Article ID 1250042, 2012.

[35] J. F. Wang and Y. M. Cheng, "A new complex variable meshless method for advection-diffusion problems," Chinese Physics B, vol. 22, no. 3, Article ID 130208, 2013.

[36] L. Chen, H. P. Ma, and Y. M. Cheng, "Combining the complex variable reproducing kernel particle method and the finite element method for solving transient heat conduction problems," Chinese Physics B, vol. 22, no. 5, Article ID 130202, 2013.
[37] H. P. Ren and Y. M. Cheng, "The interpolating elementfree Galerkin (IEFG) method for two-dimensional elasticity problems," International Journal of Applied Mechanics, vol. 3, no. 4, pp. 735-758, 2011.

[38] J. F. Wang, F. X. Sun, and Y. M. Cheng, "An improved interpolating element-free Galerkin method with nonsingular weight function for two-dimensional potential problems," Chinese Physics B, vol. 21, no. 9, Article ID 090204, 2012.

[39] R. J. Cheng and Q. Wei, "Analysis of the generalized Camassa and Holm equation with the improved element-free Galerkin method," Chinese Physics B, vol. 22, no. 6, Article ID 060209, 2013.

[40] R. J. Cheng and H. X. Ge, "Analyzing the equal width wave (EW) equation with the mesh-free kp-Ritz method," Chinese Physics B, vol. 21, no. 10, Article ID 100209, 2012.

[41] R.-J. Cheng and H.-X. Ge, “The element-free Galerkin method of numerically solving a regularized long-wave equation," Chinese Physics B, vol. 21, no. 4, Article ID 040203, 2012.

[42] B.-J. Zheng and B.-D. Dai, "Improved meshless local PetrovGalerkin method for two-dimensional potential problems," Acta Physica Sinica, vol. 59, no. 8, pp. 5182-5189, 2010.

[43] L. X. Guo and B. D. Dai, "A moving Kriging interpolation-based boundary node ethod for two-dimensional potential problems," Chinese Physics B, vol. 12, no. 6, Article ID 120202, 2010.

[44] B. Zheng and B. Dai, "A meshless local moving Kriging method for two-dimensional solids," Applied Mathematics and Computation, vol. 218, no. 2, pp. 563-573, 2011.

[45] B. Dai, B. Zheng, Q. Liang, and L. Wang, "Numerical solution of transient heat conduction problems using improved meshless local Petrov-Galerkin method," Applied Mathematics and Computation, vol. 219, no. 19, pp. 10044-10052, 2013.

[46] B. Dai and Y. Cheng, "An improved local boundary integral equation method for two-dimensional potential problems," International Journal of Applied Mechanics, vol. 2, no. 2, pp. 421436, 2010.

[47] T. Belytschko, Y. Krongauz, D. Organ, M. Fleming, and P. Krysl, "Meshless methods: an overview and recent developments," Computer Methods in Applied Mechanics and Engineering, vol. 139, no. 1-4, pp. 3-47, 1996.

[48] Z. Zhang, K. M. Liew, and Y. Cheng, "Coupling of the improved element-free Galerkin and boundary element methods for two-dimensional elasticity problems," Engineering Analysis with Boundary Elements, vol. 32, no. 2, pp. 100-107, 2008.

[49] Z. Zhang, K. M. Liew, Y. Cheng, and Y. Y. Lee, "Analyzing 2D fracture problems with the improved element-free Galerkin method," Engineering Analysis with Boundary Elements, vol. 32, no. 3, pp. 241-250, 2008.

[50] Z. Zhang, J. F. Wang, Y. M. Cheng, and K. M. Liew, “The improved element-free Galerkin method for three-dimensional transient heat conduction problems," Science China Physics, Mechanics \& Astronomy, vol. 56, no. 8, pp. 1568-1580, 2013.

[51] Z. Zhang, S. Y. Hao, K. M. Liew, and Y. M. Cheng, "The improved element-free Galerkin method for two-dimensional elastodynamics problems," Engineering Analysis with Boundary Elements, vol. 37, no. 12, pp. 1576-1584, 2013.

[52] Z. Zhang, D.-M. Li, Y.-M. Cheng, and K. M. Liew, "The improved element-free Galerkin method for three-dimensional wave equation," Acta Mechanica Sinica, vol. 28, no. 3, pp. 808818, 2012.

[53] W. Ritz, "Uber eine neue methode zur losung gewisser variationsprobleme der mathematischen physic," Journal fur Reine und Angewandte Mathematik, vol. 135, no. 2, pp. 1-61, 1909. 
[54] B. J. W. S. Rayleigh, The Theory of Sound, vol. 1, Macmillan, New York, NY, USA, 1877, reprinted by Dover Publications in 1945.

[55] K. M. Liew, X. Zhao, and T. Y. Ng, "The element-free kp-Ritz method for vibration of laminated rotating cylindrical panels," International Journal of Structural Stability and Dynamics, vol. 2, no. 4, pp. 523-558, 2002.

[56] X. Zhao, T. Y. Ng, and K. M. Liew, "Free vibration of twoside simply-supported laminated cylindrical panels via the mesh-free kp-Ritz method," International Journal of Mechanical Sciences, vol. 46, no. 1, pp. 123-142, 2004.

[57] K. M. Liew, J. Wang, M. J. Tan, and S. Rajendran, "Nonlinear analysis of laminated composite plates using the mesh-free kpRitz method based on FSDT," Computer Methods in Applied Mechanics and Engineering, vol. 193, no. 45-47, pp. 4763-4779, 2004.

[58] K. M. Liew and R. J. Cheng, "Numerical study of the three-dimensional wave equation using the mesh-free kp-Ritz method," Engineering Analysis with Boundary Elements, vol. 37, no. 7-8, pp. 977-989, 2013.

[59] R. J. Cheng, L. W. Zhang, and K. M. Liew, "Modeling of biological population problems using the element-free kp-Ritz method," Applied Mathematics and Computation, vol. 227, pp. 274-290, 2014. 


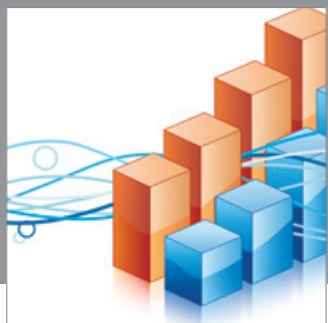

Advances in

Operations Research

mansans

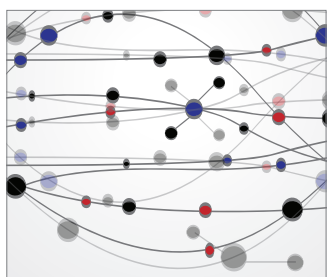

The Scientific World Journal
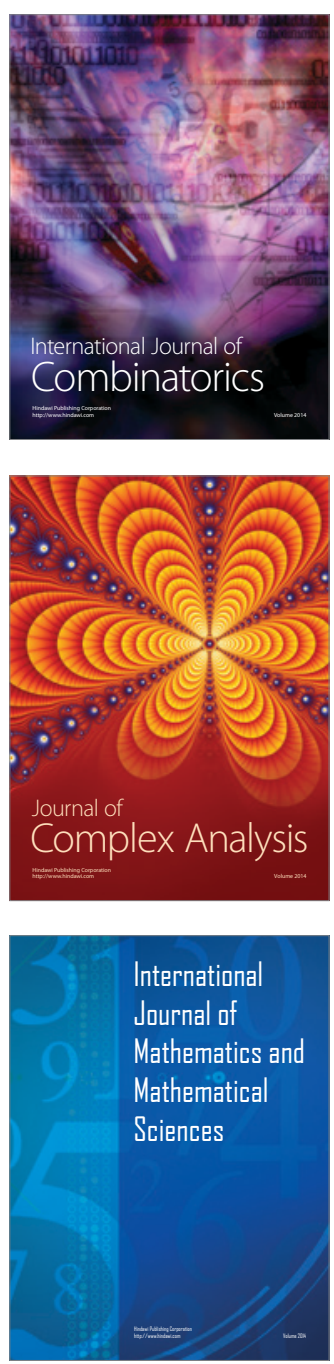
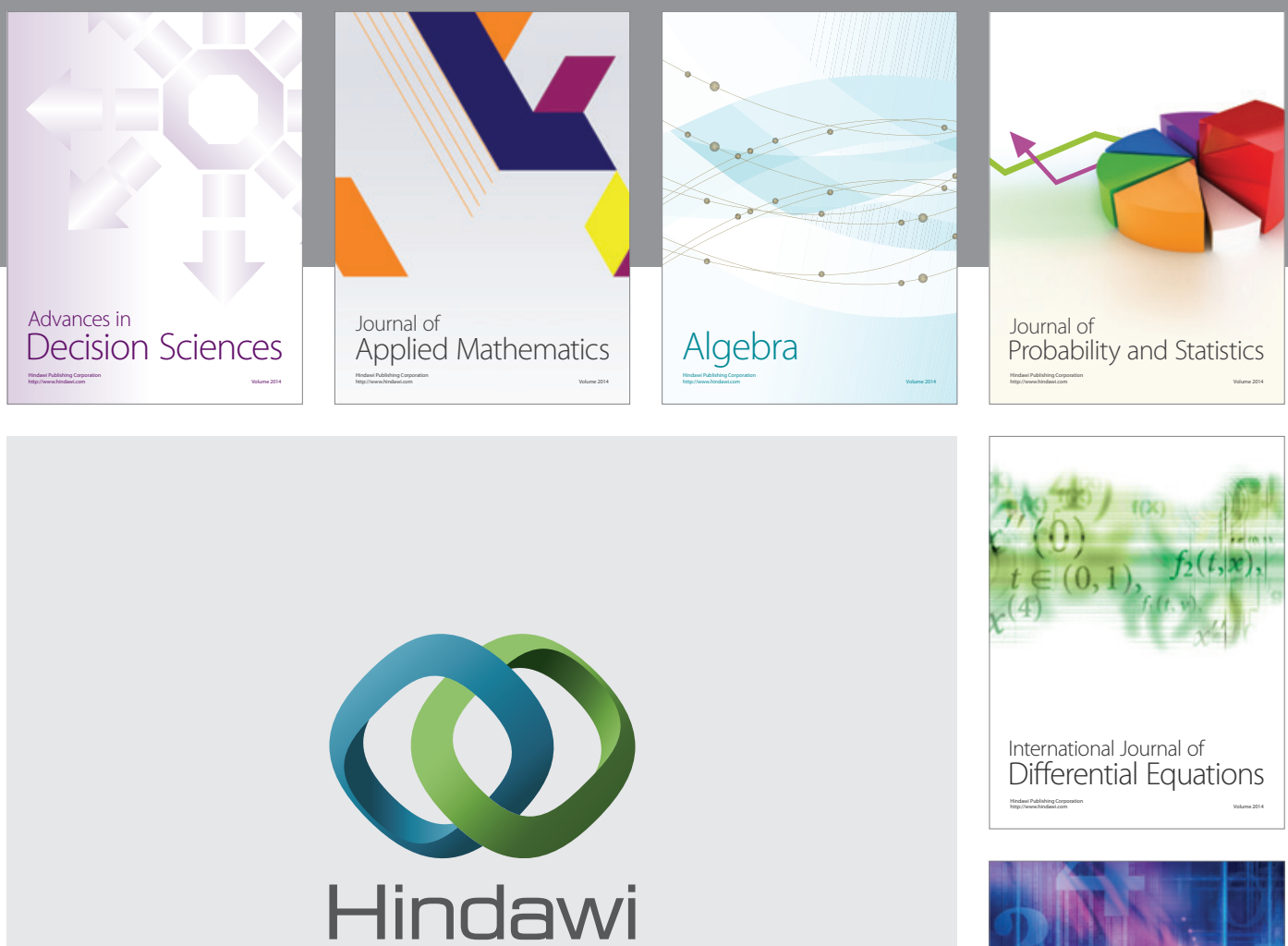

Submit your manuscripts at http://www.hindawi.com
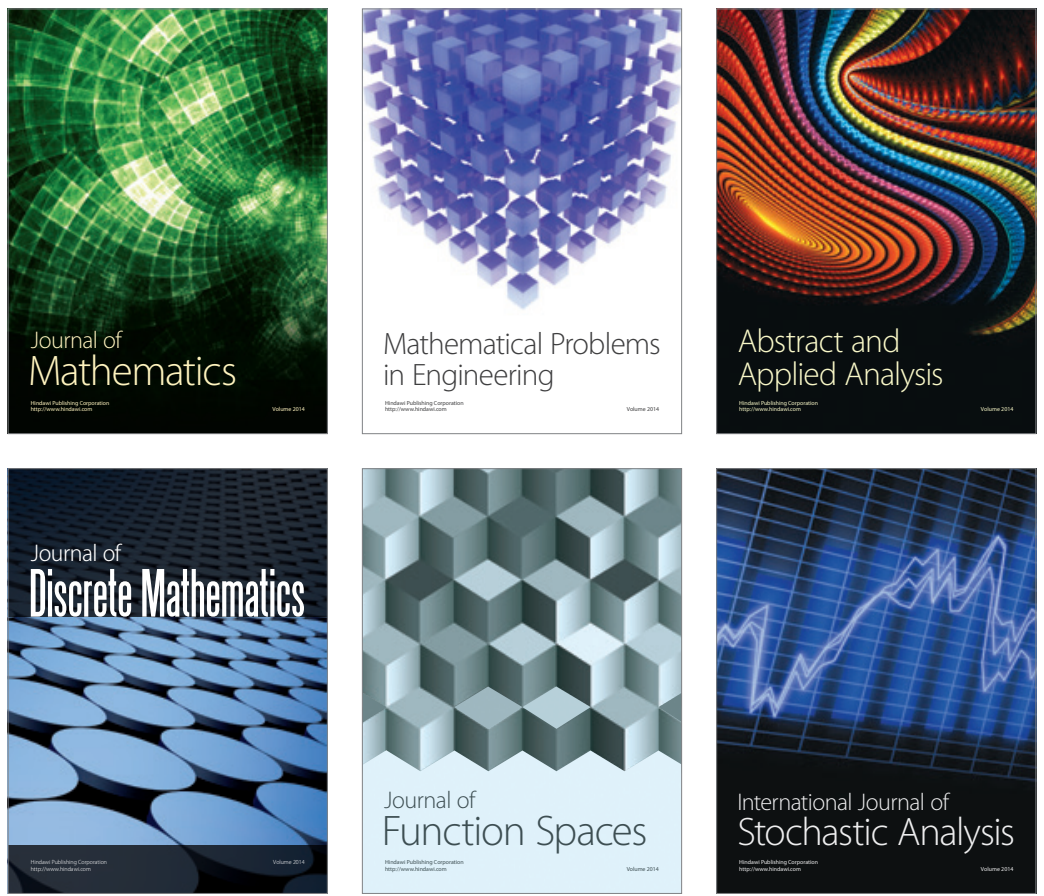

Journal of

Function Spaces

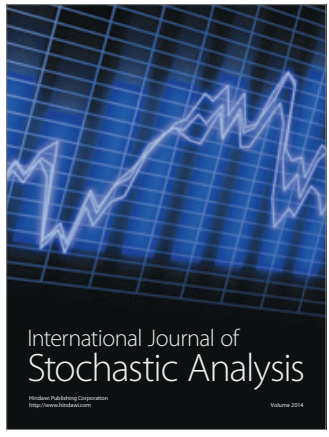

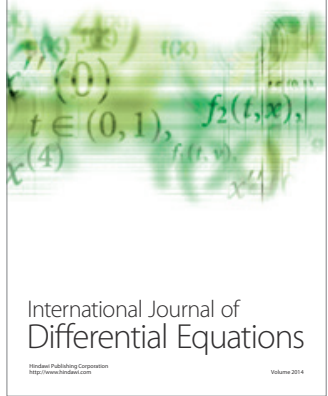
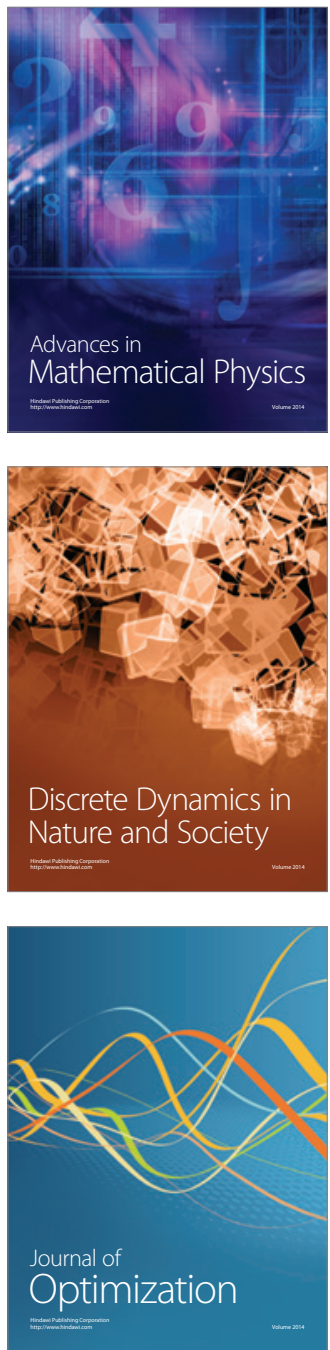